\title{
Psychosocial interventions for children and adolescents after man-made and natural disasters: a meta-analysis and systematic review
}

\author{
R. C. Brown*, A. Witt, J. M. Fegert, F. Keller, M. Rassenhofer and P. L. Plener \\ Department of Child and Adolescent Psychiatry and Psychotherapy, University Hospital Ulm, Steinhoevelstr. 5, 89075 Ulm, Germany
}

\begin{abstract}
Children and adolescents are a vulnerable group to develop post-traumatic stress symptoms after natural or man-made disasters. In the light of increasing numbers of refugees under the age of 18 years worldwide, there is a significant need for effective treatments. This meta-analytic review investigates specific psychosocial treatments for children and adolescents after man-made and natural disasters. In a systematic literature search using MEDLINE, EMBASE and PsycINFO, as well as hand-searching existing reviews and contacting professional associations, 36 studies were identified. Randomand mixed-effects models were applied to test for average effect sizes and moderating variables. Overall, treatments showed high effect sizes in pre-post comparisons (Hedges' $g=1.34$ ) and medium effect sizes as compared with control conditions (Hedges' $g=0.43$ ). Treatments investigated by at least two studies were cognitive-behavioural therapy (CBT), eye movement desensitization and reprocessing (EMDR), narrative exposure therapy for children (KIDNET) and classroom-based interventions, which showed similar effect sizes. However, studies were very heterogenic with regard to their outcomes. Effects were moderated by type of profession (higher level of training leading to higher effect sizes). A number of effective psychosocial treatments for child and adolescent survivors of disasters exist. CBT, EMDR, KIDNET and classroom-based interventions can be equally recommended. Although disasters require immediate reactions and improvisation, future studies with larger sample sizes and rigorous methodology are needed.
\end{abstract}

Received 6 June 2016; Revised 2 February 2017; Accepted 2 February 2017; First published online 11 April 2017

Key words: Adolescents, children, disasters, interventions, post-traumatic stress disorder.

\section{Introduction}

Natural and man-made disasters, like earthquakes, hurricanes, terrorist attacks or war, often lead to psychiatric impairment in child and adolescent survivors (Wang et al. 2013; Witt et al. 2015). In the light of high and steadily rising numbers of refugees worldwide (UNHCR, 2016), health care systems have to adapt to demands imposed by a group that has been subject to potentially traumatizing events, thus often resulting in a high mental health burden. Implementation of evidence-based treatments for traumatized children and adolescents has gained increasing political and public interest.

In 2014, 59.5 million people worldwide were forcibly displaced, of which 19.5 million were international refugees. Of those refugees, $51 \%$ were children and adolescents under the age of 18 years (UNHCR, 2016). In populations of child and adolescent refugees, prevalence rates of psychiatric impairment range from 20 to $80 \%$, depending on research methodology, type

\footnotetext{
* Address for correspondence: R. C. Brown, Department of Child and Adolescent Psychiatry and Psychotherapy, University Hospital Ulm, Steinhoevelstr. 5, 89075 Ulm, Germany.

(Email: rebecca.groschwitz@uniklinik-ulm.de)
}

of trauma and level of exposition to trauma. Among symptoms of depression and anxiety, symptoms of post-traumatic stress disorder (PTSD) were most commonly described in systematic reviews (Belhadj Kouider et al. 2014; Witt et al. 2015) as a prevailing mental health condition. Similar, greatly varying prevalence rates between 1 and 95\% were found in a review on the prevalence of psychopathology in children and adolescent survivors of natural disasters (Wang et al. 2013). Longitudinal studies included in both reviews showed rather persistent psychopathology over time and higher risk for psychiatric impairment in adulthood.

Due to the high risk of persisting psychological impairment in survivors of disasters, psychosocial interventions for children and adolescents have been developed over the past years. Cognitive-behavioural approaches [cognitive-behavioural therapy (CBT), i.e. trauma-focused CBT] include elements like psychoeducation, affect expression and modulation, cognitive coping, creating trauma narratives, and managing dysfunctional behaviours. CBT can be delivered as group or individual treatment and often comprises only a few sessions (around five to 10, see https://tfcbt.musc. edu). In eye movement desensitization and reprocessing (EMDR) participants focus on their most

This is an Open Access article, distributed under the terms of the Creative Commons Attribution licence (http://creativecommons.org/licenses/by/4.0/), which permits unrestricted re-use, distribution, and reproduction in any medium, provided the original work is properly cited. 
disturbing memory of the traumatic event, while they are being stimulated bilaterally, for example by rapid eye movements or tapping on their hands. EMDR can be delivered in group or individual settings and usually comprises one to five sessions (see http:// www.emdr.com). In narrative exposure therapy for children (KIDNET), patients write a script of the traumatic event and develop a narrative lifeline in order to reconsolidate and integrate traumatic events into the biography. KIDNET has only been delivered in individual settings and usually comprises 10 or more sessions (see http://www.vivo.org/en/narrativeexpositionstherapie/). As a disadvantage, CBT, EMDR and KIDNET should only be delivered by well-trained health care professionals, which might not always be available in large enough numbers after mass trauma. As an alternative, several classroom interventions (i.e. ERASE-Stress) have been developed. Classroom interventions can be delivered by teachers or trained health care professionals and can reach a large number of children and adolescents at the same time. As a disadvantage, children in need for more intense treatment might be overlooked or resources might be spent on children who were not in need for treatment. Other treatment approaches, such as the writing for recovery treatment, Mind-Body Skills Group, thought field therapy or rumination-focused therapy have been evaluated in fewer studies and often use elements of CBT, EMDR and KIDNET. One meta-analysis of literature published until 2012 showed promising results for interventions for children and adolescents after manmade and natural disasters (Newman et al. 2014). In this meta-analytic review, all interventions were shown to be effective, and CBT $(d=1.25)$, exposure therapy $(d=1.56)$ and EMDR $(d=2.15)$ showed highest effect sizes. Results were moderated by several factors (i.e. shorter duration, parental involvement, and treatment provided by health care professionals yielded more positive results). However, while 25 studies were included in the meta-analysis, results were based on only two studies on EMDR and exposure therapy, respectively. Several additional reviews have likewise pointed towards promising results for the treatment of PTSD in children and adolescents (Gillies et al. 2013; Keeshin \& Strawn, 2014), and for specific school-based interventions (Rolfsnes \& Idsoe, 2011). However, methodological challenges of those studies, along with diminished comparability of their results, have been discussed by several authors (Newman et al. 2014; Pfefferbaum et al. 2014a).

This current review and meta-analysis adds to the literature by including more recent studies published between 2002 and 2016, and by including unpublished data from intervention studies obtained by a standardized outreach procedure to professional associations of different trauma therapeutic methods. Aims of this study were to examine the effectiveness of psychosocial interventions in traumatized children and adolescents after man-made and natural disasters and to explore possible moderating factors.

\section{Method \\ Study selection}

Studies reporting on treatment outcomes regarding PTSD symptoms in children after natural or man-made disasters were identified by searching the databases Medline, EMBASE and PsycINFO. Inclusion criteria were: studies published in English or German during the years 2002 and the last date of literature search (25 August 2016), or unpublished data of studies during this time-frame, which was provided by the investigator, all participants of one study experienced the same natural or man-made disaster which was described in the study, all participants were under the age of 18 years, at least one outcome measure on distress related to the traumatic event with means and standard deviations was reported (at least prepost), all participants of one group were treated with the same treatment method, which focused on posttraumatic symptoms. Single-case studies were excluded, as means and standard deviations were needed to calculate appropriate statistics (see below). Screening of the literature was performed by three research assistants. The following keywords were used for literature search: 'mass trauma', 'PTSD', 'disaster', each paired with 'psychotherapy', 'psychosocial treatment', 'treatment' and 'intervention', respectively [e.g. in Medline: (mass trauma) AND psychotherapy]. Filters were used in each database to search for manuscripts limited to participants up to the age of 18 years and articles published between the years 2002 and 2016 (e.g. in Medline: ages restricted to child: birth18 years, publication date custom date range: 1 January 2002 to 25 August 2016). Within this literature search for original articles, 16 systematic reviews on the topic were found. Additional literature was identified from screening reference lists of those reviews (Adler-Nevo \& Manassis, 2005; Ehntholt \& Yule, 2006; Rowe \& Liddle, 2008; Salcioglu \& Basoglu, 2008; Kar, 2009; Rachamim et al. 2009; Peltonen \& Punamaki, 2010; Dorsey et al. 2011; Kowalik et al. 2011; Rolfsnes \& Idsoe, 2011; Gillies et al. 2013; Smith et al. 2013; Keeshin \& Strawn, 2014; Newman et al. 2014; Pfefferbaum et al. 2014a, b) and by contacting German and international professional associations in the field of trauma therapy (International Society for Traumatic Stress Studies, National Child Traumatic Stress Network, International Association of Trauma 
Professionals, EMDRIA Deutschland, Trauma Institut Süddeutschland, Deutschsprachige Gesellschaft für Psychotraumatologie, Deutsches Institut für Psychotraumatologie). We chose this approach, as often suddenly occurring disasters are followed by immediate help without a previous study plan. This often results in important data not being published and made available to the public. Unpublished data were received and included for six studies (Jarero et al. 2006b, c, d, 2008; Chung et al. 2014; Mehrotra, 2014). This initial search yielded 5575 studies, of which 37 were included in statistical analyses (see Fig. 1). One of those 37 studies (Jarero et al. 2006c) was excluded as an outlier (Hedges $g>10$ ). Therefore, 36 studies were included in the final analyses, reporting pre-post data from 38 samples and data from randomized controlled trials (RCTs) from 17 samples. Non-RCTs $(n=3)$ were excluded from analyses of controlled trials, as their effect sizes differed significantly from RCT outcomes. One RCT (de Roos et al. 2011) compared EMDR and CBT. Therefore, two effect sizes, one focusing on EMDR and the reversed effect size focusing on CBT, were calculated and included in the analysis. One RCT (O'Callaghan et al. 2015) compared CBT with an active control group and a waitinglist control group. In this case, effect sizes were calculated for both comparisons.

\section{Coding procedure}

Several variables were identified from included studies by two research assistants. Demographic variables (mean age, percentage of female participants, continent on which the study was conducted or the trauma took place) were coded as well as type of trauma (natural disaster, war/terrorism, accident), type of profession of treatment providers (trained therapist/psychologist/psychiatrist, other health care professional, teacher, other), measure of PTSD symptoms (PTSD symptoms by questionnaire, i.e. UCLA PTSD Reaction Index) or distress related to the traumatic event (i.e. subjective units of distress; SUD), number of sessions $(1-5,6-10,10+)$, individual or group treatment, type of therapy (EMDR, CBT, KIDNET, classroom intervention, other), and time since trauma exposure. Time since trauma was only stated in $i=18$ studies, and was mostly stated rather unspecifically (e.g. 'around 4 years ago'). Therefore, time since trauma was not chosen as a moderator. All treatments which were not specifically trauma focused, but were active control conditions to interventions were coded as control conditions. In cases where one traumafocused therapy served as control for another traumafocused therapy, analyses were run twice, considering each trauma-focused therapy as intervention and control condition, respectively. Inter-rater reliability ranged from Cohen's $\kappa=0.70$ (profession of treatment provider) to Cohen's $\kappa=1.0$ (for type of trauma and group or individual trauma). In cases where Cohen's $\kappa$ did not equal 1, studies were reviewed and a consensus-based value was chosen.

If one study compared two intervention groups (i.e. de Roos et al. 2011), those scores were separated and treated as individual sources. Since only a small number of studies provided follow-up scores, the score measured closest to the end of the intervention was identified as a post-score and follow-up scores were excluded.

Quality of studies was not assessed systematically and was therefore not included in analyses.

\section{Statistical analyses}

Statistical analyses were conducted using $R$, a software for statistical computing and graphics ( $R$ Development Core Team, 2008) and the package metafor (Viechtbauer, 2010). In order to correct for small-sample bias in the Cohen's $d$ measure, Hedges' $g$ was calculated with $g=x 1-x 2 / s^{*}[x$ corresponding to the respective measure $(x 1=$ mean of pre-measure or study 1 and $x 2=$ mean of post-measure or study 2)] and $s *=\sqrt{(n 1-1) s 1^{2}+(n 2-1) s 2^{2} / n 1+n 2-2} \quad(n 1=$ number of participants pre-treatment or in study 1 , $n 2=$ number of participants post-treatment or study 2; $s 1$ or $s 2=$ standard deviation respective to $x 1$ or $x 2$ ) for pre-post and intervention $v$. control group comparisons, respectively (Hedges, 1981). Effect sizes were weighted using the inverse variance method, where effect sizes with smaller variance were given more weight in the analyses than those with larger variance.

A random-effects model was chosen for evaluation of the average treatment effects, since the included studies differed in their methods and characteristics of the included samples. The model was given by $\theta_{i}$ $=\mu+u_{i}$, with $\theta_{i}$ being the true (unknown) corresponding effect to each $i$ th study, $\mu$ being the mean true effect and with $u_{\tau} N\left(0, r^{2}\right)$, with $r^{2}$ being the overall variance of true effects.

In order to examine how much moderator variables contributed to the variance of the true effect calculated in the random-effects model, a mixed-effects model was chosen. The model was given by $\theta_{i}=\beta_{0}+\beta_{1 x i 1}$ $+\ldots+\beta_{j x i j}+u_{i}$ with again, $u_{i} \sim N\left(0, r^{2}\right), \beta$ representing the weight of $x i j$, which represents the value of the $j$ th moderator variable of the $i$ th study (Viechtbauer, 2010). Two separate analyses were conducted for pre-post comparisons of $n=32$ samples and intervention $v$. control comparisons of $n=16$ samples. Moderators were entered separately to the model. 


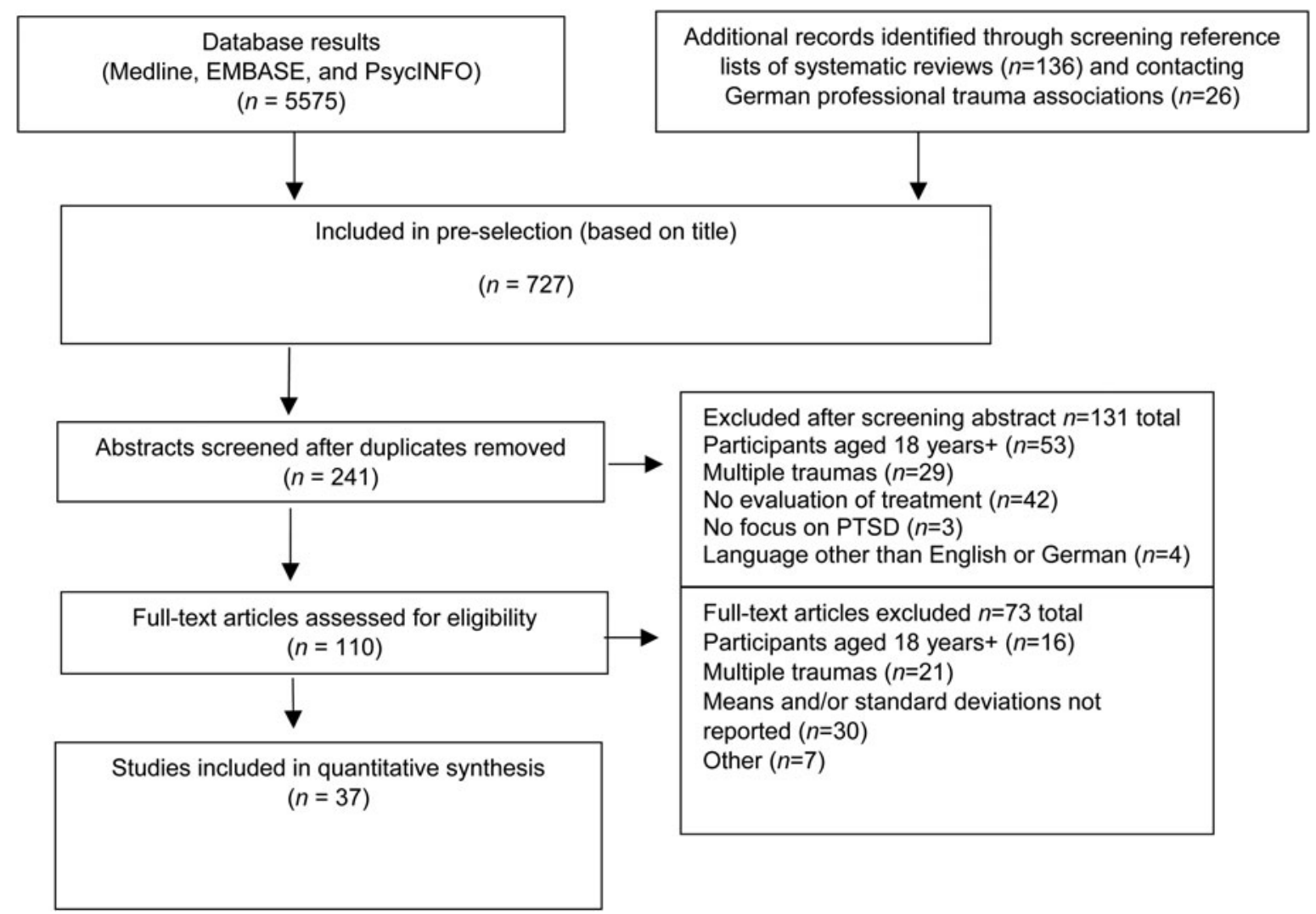

Fig. 1. Process of identifying appropriate studies, following Preferred Reporting Items for Systematic Reviews and Meta-Analyses (PRISMA) guidelines. PTSD, Post-traumatic stress disorder.

A univariate analysis of variance (ANOVA), weighted for inverse variance, was calculated for differences of type of treatment.

\section{Results}

Across all 36 studies included in this review, $n=3541$ children and adolescents were treated with a specific therapy (mean $=93.18$, S.D. $=163.23$ ) and $n=870$ served as a control group (mean $=48.33$, S.D. $=36.49)$. On average, $50.53 \%$ (S.D. $=16.18$ ) of all participants were female (gender stated in $i=35$ studies) and the average age was 11.9 years (S.D. $=2.40$ ) (age stated in $i=28$ studies). Participants received an average of 8.43 (S.D. $=7.52$ ) therapy sessions (stated in all $i=36$ studies). On average, time since trauma was 130 weeks (s.D. $=169.85$ ), ranging from 'the immediate aftermath' to 12 years. However, it has to be kept in mind that time since trauma was only reported in $i=18$ studies.

In $i=17$ studies, children had experienced trauma related to war or terrorism, $i=15$ studies were conducted after experiences of natural disasters, and in $i$ $=4$ studies participants had been exposed to a major public accident (e.g. explosion of a factory). While most of the studies were carried out in Asia and the
Middle East ( $i=11$ and $i=9$, respectively), relatively few studies were conducted in Africa, Europe, or South and North America. Most studies included in this review investigated the effect of EMDR $(i=10)$, while $i=9$ researched classroom-based interventions, $i=8$ focused on CBT, and $i=2$ on KIDNET. While in $i=17$ studies trained psychologists/psychiatrists/therapists provided therapy, in 10 studies teachers were the sole providers of interventions. Most interventions $(n=28)$ were group interventions, while $n=8$ were delivered individually.

\section{Pre-post data: effect sizes}

Results from the random-effects model showed a large effectiveness across all studies of therapies specifically designed for the treatment of PTSD symptoms for children and adolescents $[g=1.35,95 \%$ confidence interval (CI) 1.02-1.68] when comparing symptomatology before and after treatment. As can be seen in the forest plot (Fig. 2), there was a large heterogeneity across studies $(Q=536.88, p<0.0001)$. However, all studies showed positive effect sizes ranging from $g=0.09$ (Thabet et al. 2005) to $g=4.19$ (Sakai et al. 2010).

Taken together, $68.44 \%$ of the contribution to the overall variance of the effect size was accounted for 


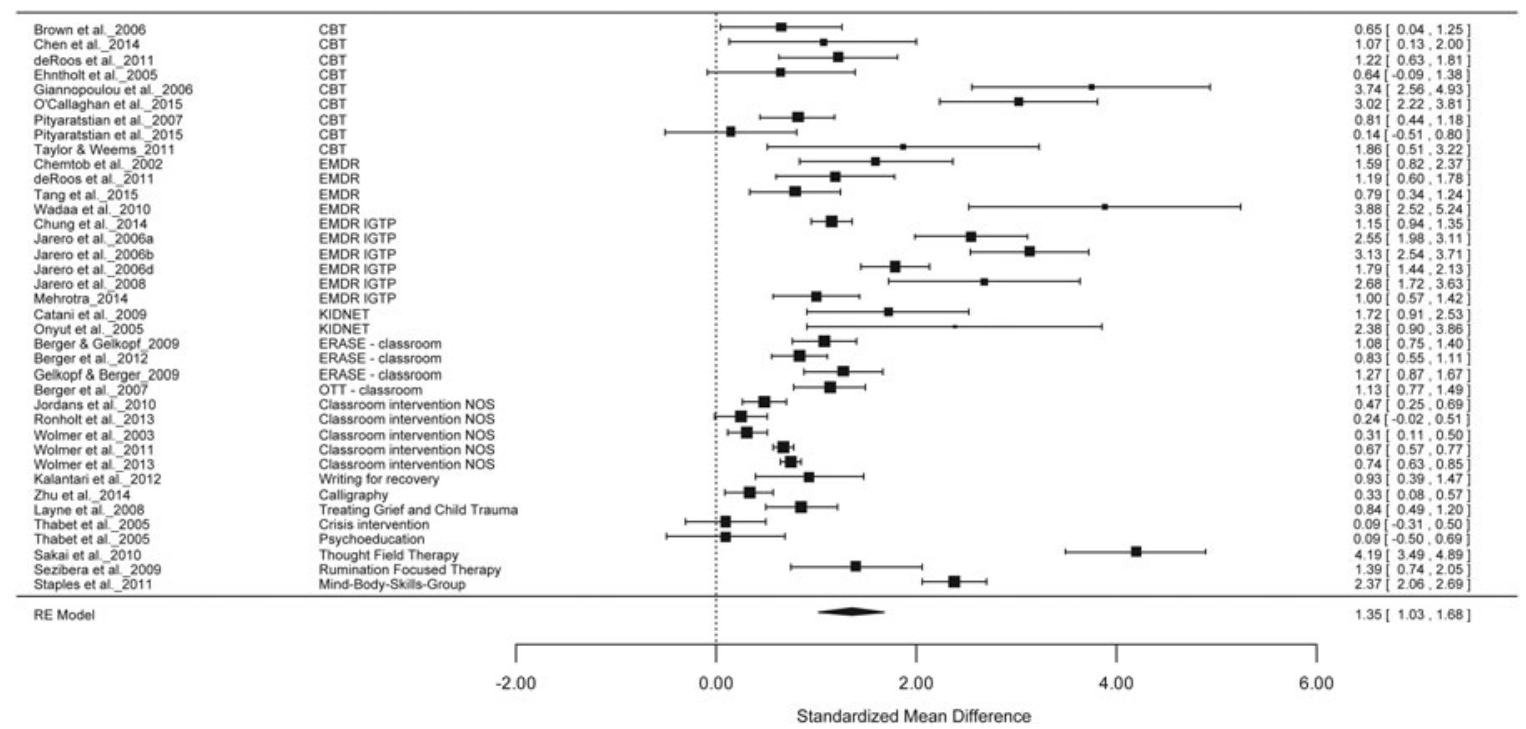

Fig. 2. Forest plot of effect sizes of pre-post comparisons. RE, Random-effects; CBT, cognitive-behavioural therapy; EMDR, eye movement desensitization and reprocessing; EMDR-IGTP, EMDR Integrative Group Treatment Protocol; KIDNET, narrative exposure therapy for children; ERASE, Erase-Stress classroom intervention; OTT, Overshadowing the Threat of Terrorism classroom intervention; NOS, not otherwise specified. Values are standardized mean differences, with $95 \%$ confidence intervals.

by studies on school-based interventions. Studies on EMDR contributed $13.37 \%$, studies on CBT $5.17 \%$, and studies on KIDNET $0.48 \%$. Studies on other interventions (writing for recovery, calligraphy, treating grief and child trauma, crisis intervention group, psychoeducation group, thought field therapy, MindBody Skills Group, and rumination-focused therapy) contributed the remaining $12.54 \%$ to the overall effect size.

Results of an ANOVA (weighted for inverse variance) did not show a significant difference between types of therapy $(F=2.49, p=0.062)$, with KIDNET showing the highest average effect size (mean $=1.87$, S.D. $=0.77$ ), followed by EMDR (mean $=1.46$, S.D. $=$ 3.17) and CBT (mean=1.07, S.D. $=2.72$ ). Classroombased interventions showed an average effect (mean $=0.68$, s.D. $=2.38$ ).

\section{Pre-post data: moderators}

The following moderators were examined: age and gender of participants, type of trauma, continent the study was carried out in, profession of treatment providers, method of intervention, number of sessions, measure of PTSD symptoms (PTSD symptoms or general impairment after traumatic events), individual or group treatment.

Results from the mixed-effects model showed that only profession of treatment providers, measure of PTSD symptoms and individual or group treatment significantly moderated the results. While there were no differences between psychiatrists/psychologists/ therapists, other health care professionals (i.e. nurses), or other professions (i.e. volunteers), effect sizes were significantly lower if health care providers were teachers $\left(\gamma_{\text {teacher }}=-1.05, Z=-2.77, p<0.01\right)$. Effect sizes were also significantly lower if treatment was delivered in a group setting $\left(\gamma_{\text {group }}=-0.83, Z=-2.09, p<\right.$ $0.05)$ rather than in individual settings. If treatment effects were rated by general impairment (i.e. SUD) rather than questionnaires assessing all PTSD symptoms, effect sizes were significantly higher $\left(\gamma_{\text {assessment }}\right.$ $=0.83, Z=1.97, p<0.05$ ).

\section{RCTs: effect sizes}

Overall, treatments were more effective than respective control groups ( $g=0.44,95 \%$ CI $0.18-0.69$ ). However, there was a significant heterogeneity between studies $(Q=119.69, p<0.0001)$. Effect sizes ranged from $g$ $=-0.17$ (de Roos et al. 2011, comparison of CBT and EMDR) to $g=1.41$ (Mehrotra, 2014). Classroom-based interventions contributed most to the variance (44.69\%), followed by studies on EMDR (14.05\%), one study on calligraphy (10.94\%), CBT (10.47\%) and KIDNET $(1.70 \%)$. Studies on other therapies contributed the remaining $18.15 \%$ to the overall variance of the effect size (see Fig. 3 for details).

An ANOVA (weighted for inverse variance) did not show significant differences between different types of treatment. 


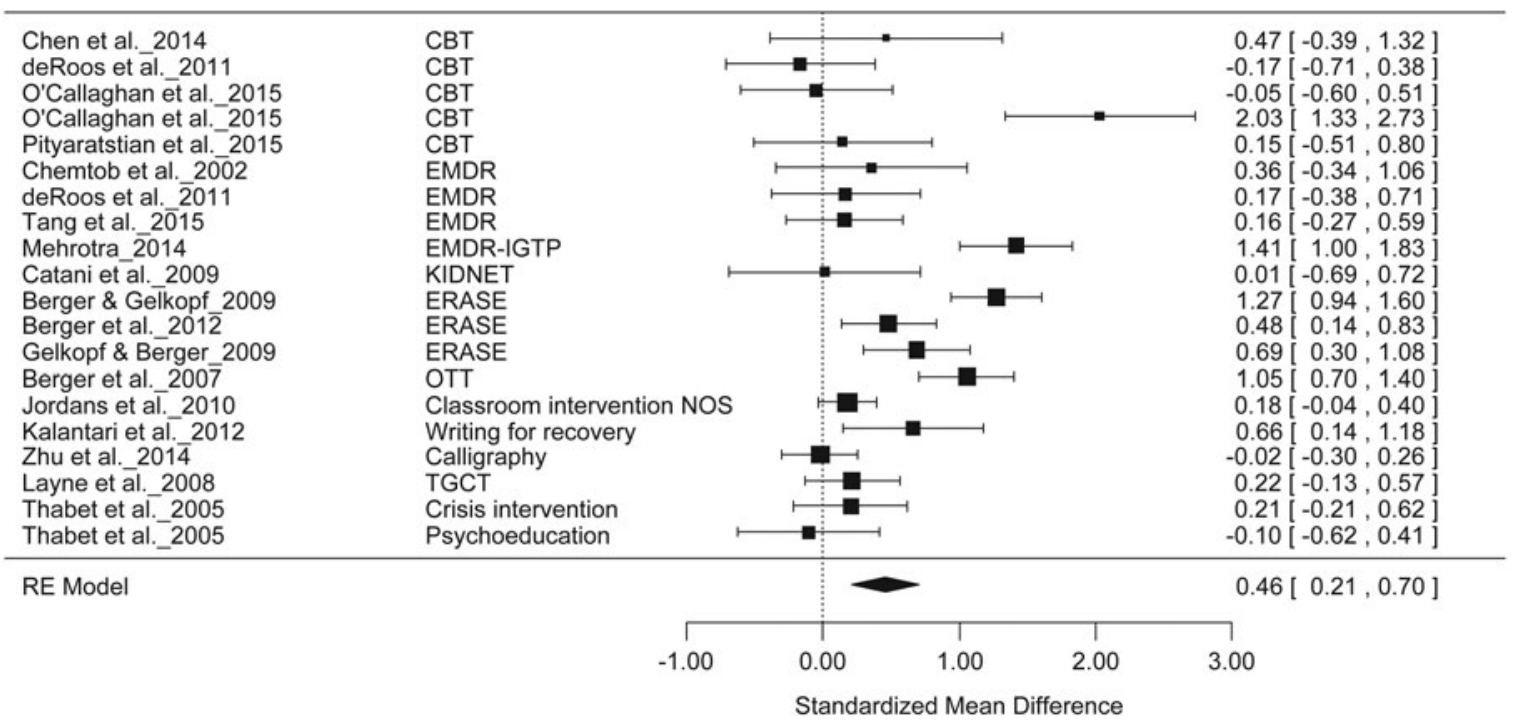

Fig. 3. Forest plot of effect sizes of intervention $v$. control condition comparisons. RE, Random-effects; CBT, cognitivebehavioural therapy; EMDR, eye movement desensitization and reprocessing; EMDR-IGTP, EMDR Integrative Group Treatment Protocol; KIDNET, narrative exposure therapy for children; ERASE, Erase-Stress classroom intervention; OTT, Overshadowing the Threat of Terrorism classroom intervention; NOS, not otherwise specified; TGCT, trauma and grief component therapy. Values are standardized mean differences, with $95 \%$ confidence intervals.

\section{RCTs: moderators}

The following moderators were entered in the mixed-effects model: age and gender of participants, type of trauma, continent the study was carried out in, profession of treatment providers, method of intervention, number of sessions, individual or group treatment. Unlike analyses of pre-post data, type of assessment of PTSD symptoms was not included, since only one study (Kalantari et al. 2012) used a measure of general impairment, while the other studies used measures which assessed PTSD symptoms. None of the variables entered significantly moderated the outcomes.

\section{Discussion}

This meta-analytic review comprised results from 32 studies on $n=3260$ children and adolescents who had all experienced or witnessed a mass traumatic event (natural disaster, war/terrorism-related event, mass accident). Overall, results showed treatments to be very effective when comparing impairment before and after therapy, and also showed to be effective as compared with control groups.

When comparing pre- with post-scores, an overall effect size of $g=1.35$ was found, which indicates a very strong relative reduction of PTSD symptoms. These results are in line with findings of a metaanalytic review conducted on a comparable subset of studies (Newman et al. 2014), who found an overall effect size of $d=1.13$. However, since traumatic events included in this study were mainly single trauma, for example natural disasters, part of this effect may have been due to spontaneous remission (average time since trauma was 130 weeks, in studies which provided appropriate data). This is supported by a meta-analytic review on long-term spontaneous remission of PTSD symptoms in adults: Morina et al. (2014) found rates of remission without therapy to be highest after natural disasters. In fact, the remission rate after natural disasters was $60 \%$, as compared with physical disease, with $31.4 \%$. In the same line, Weems \& Graham (2014) only found persisting psychiatric impairment in $15 \%$ of youth who had been exposed to a hurricane. Therefore, results on the effectiveness of treatments for PTSD in pre-post comparison (especially after single trauma) have to be interpreted with much care and our findings are not indicative for treatment of other forms of repetitive, severe traumatization.

Type of trauma (natural disaster, war, accident or terrorism) did not moderate treatment effect sizes. In their meta-analysis on remission rates of PTSD, Morina et al. (2014) did not find differences between natural disasters, war, terrorist attacks or accidents. Therefore, psychological impact of those events might be similar in terms of remission from PTSD rates. However, to the best of our knowledge, no study has yet statistically investigated the effect of type of disaster (excluding interpersonal violence and type 2 trauma) in relation to different treatment 
methods. Furthermore, not all types of trauma were treated with all treatment methods (i.e. EMDR studies mainly focused on natural disasters, while KIDNET studies mainly focused on war). Therefore, it might be that different kinds of treatments are indicated after different types of disasters, but further systematic research is needed to shed light on this matter.

When comparing different types of treatment methods (EMDR, CBT, KIDNET and classroom-based interventions), there were no significant differences between types of therapy.

In pre-post comparisons, results were moderated by type of profession (with teachers and unqualified staff yielding lower effect sizes) and treatment setting (with group treatment yielding lower effect sizes). Although these results might be associated with classroom-based interventions yielding slightly lower effect sizes than other treatments, high qualification of treatment providers seems to be a core element to effective treatment. These results are also in line with the meta-analyses by Newman et al. (2014). Although the support of helpers without professional mental health care qualification can be crucial in times of crisis, this finding is of importance for planning further large-scale interventions. This could point to the feasibility of using stepped-care approaches to deliver mental health support to large numbers of people in need at the same time. Doing so will both assure rapid lower-level care by less qualified helpers and higher-level care by mental health professionals for those in need of intensive interventions. Not surprisingly, results were also moderated by assessment method of symptoms, with less reliable and less valid assessment methods (i.e. SUD) yielding higher effect sizes. Since $50 \%$ of the studies on EMDR did not assess specific PTSD symptoms, but general distress in relation to the traumatic event, results on EMDR need to be interpreted with care.

Overall, all treatment methods which were evaluated by at least two studies (CBT, EMDR, KIDNET and classroom interventions) showed high effect sizes in pre-post comparisons. However, results have to be interpreted with much care, as (1) rates of spontaneous remission were not accounted for, (2) treatments with the highest effect sizes only contributed little to the overall effect and would need to be evaluated in larger samples, (3) in a large number of studies showing high effect sizes, PTSD symptoms were not evaluated specifically.

In order to control for the effect of spontaneous remission, data of comparisons of treatment and control groups were analysed. In comparison with prepost designs, the effect size was naturally smaller $(g=0.44)$. Nevertheless, these results show an additional effect in the reduction of PTSD symptoms to the effect of possible spontaneous remission and underline the importance of treatment after single trauma, even though rates of spontaneous remission are quite high. Treatment methods did not differ significantly in their effect sizes. However, there was a high heterogeneity of effect sizes among studies evaluating the same treatment method. While EMDR and KIDNET had shown significantly higher effect sizes than classroom-based interventions in pre-post comparisons, those differences were no longer significant. On the contrary, results showed smaller effect sizes than classroom-based interventions (except for one study evaluating EMDR; Mehrotra, 2014).

Overall, these results showed treatment of PTSD symptoms after traumatic events to be more effective than spontaneous remission. Treatment methods which showed superior effect sizes in pre-post comparisons were no longer more effective than other methods in controlled study designs.

\section{Limitations and strengths}

Several limitations have to be considered when interpreting results of this review. First, studies were very heterogenic with regard to several factors (such as sample size, use and type of control group). Time-frames in which the pre- and post-assessments were conducted were heterogenic. This factor was not controlled for, since a majority of the studies did not specify the time point of evaluation. Studies also differed in their use of assessment tools, which moderated results significantly. Furthermore, the time-frame of when therapy started after the traumatic event was not accounted for, since it was not reported consistently in a large number of studies. In the metaanalytic review by Newman et al. (2014) interventions delivered 4 months after the traumatic event yielded the largest effect sizes. As a further limitation, quality of studies was not assessed systematically and was not part of the analyses. However, on a descriptive level, as can be seen in in Table 1, studies were heterogenic in their quality [e.g. type of study (pre-post $v$. RCT), use of assessment tools (SUD $v$. validated assessment tool), or sample size $(n=6 v \cdot n=754)]$, which may have biased results. Furthermore, some possible moderators could not be explored due to the small number of studies reporting data and the heterogeneity between them. Where moderators were analysed, it is possible that analyses were underpowered, due to the small number of studies. Due to the search strategy of screening titles before screening abstracts, relevant articles may have been missed. However, given that former systematic reviews on this topic (e.g. Newman et al. 2014) reported lower numbers of included studies, it seems reasonable to suggest that our strategy was feasible in detecting an adequate 
Table 1. Included studies

\begin{tabular}{|c|c|c|c|c|c|c|c|c|c|c|c|c|}
\hline Study & $\begin{array}{l}\text { Therapy } \\
\text { method }\end{array}$ & $\begin{array}{l}\text { Type of } \\
\text { trauma }\end{array}$ & Continent & $\begin{array}{l}\text { Type of } \\
\text { study }\end{array}$ & $\begin{array}{l}\text { Intervention } \\
\text { group, } n\end{array}$ & $\begin{array}{l}\text { Control } \\
\text { group, } \\
n\end{array}$ & $\begin{array}{l}\text { Assessment } \\
\text { tool }\end{array}$ & $\begin{array}{l}\text { Group/ } \\
\text { individual }\end{array}$ & $\begin{array}{l}\text { Number } \\
\text { of } \\
\text { sessions }\end{array}$ & $\begin{array}{l}\text { Profession } \\
\text { of treatment } \\
\text { provider }\end{array}$ & $\begin{array}{l}\text { Age of } \\
\text { participants, } \\
\text { years }\end{array}$ & $\begin{array}{l}\% \\
\text { Female }\end{array}$ \\
\hline $\begin{array}{l}\text { Brown et al. } \\
\text { (2006) }\end{array}$ & CBT & War/terrorism & $\begin{array}{l}\text { North } \\
\text { America }\end{array}$ & Waitlist control & 22 & & CPSS & Group & 10 & $\begin{array}{l}\text { Health care } \\
\text { specialist }\end{array}$ & 10.3 & 63.3 \\
\hline $\begin{array}{l}\text { Chen et al. } \\
\text { (2014) }\end{array}$ & CBT & $\begin{array}{l}\text { Natural } \\
\text { disaster }\end{array}$ & Asia & $\begin{array}{l}\text { RCT - active } \\
\text { control }\end{array}$ & 10 & 12 & CRIES-13 & Group & 6 & $\begin{array}{l}\text { Health care } \\
\text { specialist }\end{array}$ & 14.5 & 68.0 \\
\hline $\begin{array}{l}\text { de Roos et al. } \\
\text { (2011) }\end{array}$ & CBT/EMDR & Accident & Europe & $\begin{array}{l}\text { RCT - active } \\
\text { control }\end{array}$ & $26 / 26$ & $26 / 26$ & PROPS & Individual & $4 / 3$ & $\begin{array}{l}\text { Psychiatrist/ } \\
\text { psychologist }\end{array}$ & 10.1 & 44.3 \\
\hline $\begin{array}{l}\text { Ehntholt et al. } \\
\text { (2005) }\end{array}$ & CBT & War/terrorism & Europe & Waitlist control & 15 & & CRIES & Group & 6 & Teacher & 12.5 & 33.3 \\
\hline $\begin{array}{l}\text { Giannopoulou } \\
\text { et al. (2006) }\end{array}$ & CBT & $\begin{array}{l}\text { Natural } \\
\text { disaster }\end{array}$ & Europe & Waitlist control & 15 & & CRIES-13 & Group & 6 & $\begin{array}{l}\text { Psychiatrist/ } \\
\text { psychologist }\end{array}$ & 9.6 & 55.0 \\
\hline $\begin{array}{c}\text { O'Callaghan } \\
\text { et al. (2015) }\end{array}$ & CBT & War/terrorism & Africa & $\begin{array}{l}\text { RCT - active } \\
\text { control }\end{array}$ & 26 & 24 & UCLA & Group & 9 & Other & 14.8 & 42.0 \\
\hline $\begin{array}{c}\text { Pityaratstian } \\
\text { et al. (2007) }\end{array}$ & CBT & $\begin{array}{l}\text { Natural } \\
\text { disaster }\end{array}$ & Asia & Waitlist control & 61 & & CRIES & Group & 2 & $\begin{array}{l}\text { Health care } \\
\text { specialist }\end{array}$ & 10.5 & 59.4 \\
\hline $\begin{array}{c}\text { Pityaratstian } \\
\text { et al. (2015) }\end{array}$ & CBT & $\begin{array}{l}\text { Natural } \\
\text { disaster }\end{array}$ & Asia & $\begin{array}{l}\text { RCT - waitlist } \\
\text { control }\end{array}$ & 18 & 18 & UCLA & Group & 3 & $\begin{array}{l}\text { Psychiatrist/ } \\
\text { psychologist }\end{array}$ & 12.25 & 72.2 \\
\hline $\begin{array}{l}\text { Taylor \& } \\
\text { Weems (2011) }\end{array}$ & CBT & $\begin{array}{l}\text { Natural } \\
\text { disaster }\end{array}$ & $\begin{array}{l}\text { North } \\
\text { America }\end{array}$ & Pre-post & 6 & & CPTSD-RI & Individual & 10 & $\begin{array}{l}\text { Psychiatrist/ } \\
\text { psychologist }\end{array}$ & 9.8 & 66.6 \\
\hline $\begin{array}{l}\text { Chemtob et al. } \\
\text { (2002) }\end{array}$ & EMDR & $\begin{array}{l}\text { Natural } \\
\text { disaster }\end{array}$ & $\begin{array}{l}\text { North } \\
\text { America }\end{array}$ & $\begin{array}{l}\text { RCT - waitlist } \\
\text { control }\end{array}$ & 17 & 15 & CRIES & Individual & 3 & $\begin{array}{l}\text { Psychiatrist/ } \\
\text { psychologist }\end{array}$ & 8.4 & 73.0 \\
\hline $\begin{array}{l}\text { Tang et al. } \\
\text { (2015) }\end{array}$ & EMDR & $\begin{array}{l}\text { Natural } \\
\text { disaster }\end{array}$ & Asia & $\begin{array}{l}\text { RCT - active } \\
\text { control }\end{array}$ & 41 & 42 & CRIES & Individual & 36 & $\begin{array}{l}\text { Psychiatrist/ } \\
\text { psychologist }\end{array}$ & 14.2 & 53.7 \\
\hline $\begin{array}{l}\text { Wadaa et al. } \\
\text { (2010) }\end{array}$ & EMDR & War/terrorism & Asia & Waitlist control & 12 & & UCLA & Individual & 12 & $\begin{array}{l}\text { Psychiatrist/ } \\
\text { psychologist }\end{array}$ & 11.4 & 51.7 \\
\hline $\begin{array}{l}\text { Chung et al. } \\
\text { (2014) }\end{array}$ & EMDR-IGTP & Accident & Asia & Pre-post & 210 & & SUD & Group & 1 & $\begin{array}{l}\text { Psychiatrist/ } \\
\text { psychologist }\end{array}$ & & 48.4 \\
\hline $\begin{array}{c}\text { Jarero et al. } \\
(2006 a)\end{array}$ & EMDR-IGTP & $\begin{array}{l}\text { Natural } \\
\text { disaster }\end{array}$ & $\begin{array}{l}\text { South } \\
\text { America }\end{array}$ & Pre-post & 44 & & CRTES & Group & 1 & $\begin{array}{l}\text { Psychiatrist/ } \\
\text { psychologist }\end{array}$ & & 50.0 \\
\hline $\begin{array}{c}\text { Jarero et al. } \\
(2006 b)\end{array}$ & EMDR-IGTP & $\begin{array}{l}\text { Natural } \\
\text { disaster }\end{array}$ & $\begin{array}{l}\text { South } \\
\text { America }\end{array}$ & Pre-post & 50 & & SUD & Group & 1 & $\begin{array}{l}\text { Psychiatrist/ } \\
\text { psychologist }\end{array}$ & 8.4 & 30.0 \\
\hline $\begin{array}{l}\text { Jarero et al. } \\
(2006 d)\end{array}$ & EMDR-IGTP & $\begin{array}{l}\text { Natural } \\
\text { disaster }\end{array}$ & $\begin{array}{l}\text { South } \\
\text { America }\end{array}$ & Pre-post & 89 & & SUD & Group & 1 & $\begin{array}{l}\text { Psychiatrist/ } \\
\text { psychologist }\end{array}$ & 8.6 & 51.7 \\
\hline $\begin{array}{l}\text { Jarero et al. } \\
(2008)\end{array}$ & EMDR-IGTP & Accident & $\begin{array}{l}\text { South } \\
\text { America }\end{array}$ & Pre-post & 16 & & CRTES & Group & 1 & $\begin{array}{l}\text { Psychiatrist/ } \\
\text { psychologist }\end{array}$ & & 31.3 \\
\hline
\end{tabular}




\begin{tabular}{|c|c|c|c|c|c|c|c|c|c|c|c|c|}
\hline $\begin{array}{l}\text { Mehrotra } \\
(2014)\end{array}$ & EMDR-IGTP & $\begin{array}{l}\text { Natural } \\
\text { disaster }\end{array}$ & Asia & $\begin{array}{l}\text { RCT waitlist } \\
\text { control }\end{array}$ & 47 & 69 & CRIES-8 & Group & 2 & $\begin{array}{l}\text { Psychiatrist/ } \\
\text { psychologist }\end{array}$ & & \\
\hline $\begin{array}{l}\text { Catani et al. } \\
\text { (2009) }\end{array}$ & KIDNET & $\begin{array}{l}\text { Natural } \\
\text { disaster }\end{array}$ & Asia & $\begin{array}{l}\text { RCT - active } \\
\text { control }\end{array}$ & 16 & 15 & UPID & Individual & 6 & $\begin{array}{l}\text { Health care } \\
\text { specialist }\end{array}$ & 11.9 & 37.5 \\
\hline $\begin{array}{l}\text { Onyut et al. } \\
\text { (2005) }\end{array}$ & KIDNET & War/terrorism & Africa & Pre-post & 6 & & CIDI & Individual & 5 & $\begin{array}{l}\text { Psychiatrist/ } \\
\text { psychologist }\end{array}$ & 15.3 & 50.0 \\
\hline $\begin{array}{l}\text { Berger \& } \\
\text { Gelkopf } \\
(2009)\end{array}$ & $\begin{array}{l}\text { ERASE - } \\
\text { classroom }\end{array}$ & $\begin{array}{l}\text { Natural } \\
\text { disaster }\end{array}$ & Asia & $\begin{array}{l}\text { RCT waitlist } \\
\text { control }\end{array}$ & 84 & 82 & UCLA & Group & 12 & Teacher & & 41.7 \\
\hline $\begin{array}{l}\text { Berger et al. } \\
(2012)\end{array}$ & $\begin{array}{l}\text { ERASE - } \\
\text { classroom }\end{array}$ & War/terrorism & $\begin{array}{l}\text { Middle } \\
\text { East }\end{array}$ & $\begin{array}{l}\text { RCT waitlist } \\
\text { control }\end{array}$ & 107 & 47 & UCLA & Group & 16 & Teacher & 12.8 & 56.1 \\
\hline $\begin{array}{l}\text { Gelkopf \& } \\
\text { Berger (2009) }\end{array}$ & $\begin{array}{l}\text { ERASE - } \\
\text { classroom }\end{array}$ & War/terrorism & $\begin{array}{l}\text { Middle } \\
\text { East }\end{array}$ & $\begin{array}{l}\text { RCT waitlist } \\
\text { control }\end{array}$ & 58 & 49 & UCLA & Group & 12 & Teacher & 13.1 & .0 \\
\hline $\begin{array}{l}\text { Berger et al. } \\
(2007)\end{array}$ & OTT - classroom & War/terrorism & $\begin{array}{l}\text { Middle } \\
\text { East }\end{array}$ & $\begin{array}{l}\text { RCT waitlist } \\
\text { control }\end{array}$ & 70 & 72 & UCLA & Group & 8 & Teacher & & 44.3 \\
\hline $\begin{array}{l}\text { Jordans et al. } \\
\text { (2010) }\end{array}$ & $\begin{array}{l}\text { Classroom } \\
\text { intervention } \\
\text { NOS }\end{array}$ & War/terrorism & Asia & $\begin{array}{l}\text { RCT waitlist } \\
\text { control }\end{array}$ & 164 & 161 & CPSS & Group & 15 & Other & 12.7 & 55.5 \\
\hline $\begin{array}{l}\text { Ronholt et al. } \\
\text { (2013) }\end{array}$ & $\begin{array}{l}\text { Classroom } \\
\text { intervention } \\
\text { NOS }\end{array}$ & Accident & Europe & Pre-post & 108 & & Darryl & Group & 5 & $\begin{array}{l}\text { Psychiatrist/ } \\
\text { psychologist }\end{array}$ & & 63.9 \\
\hline $\begin{array}{l}\text { Wolmer et al. } \\
\text { (2003) }\end{array}$ & $\begin{array}{l}\text { Classroom } \\
\text { intervention } \\
\text { NOS }\end{array}$ & $\begin{array}{l}\text { Natural } \\
\text { disaster }\end{array}$ & $\begin{array}{l}\text { Middle } \\
\text { East }\end{array}$ & Pre-post & 202 & & PTSDI-RI & Group & 8 & Teacher & 8.2 & 56.0 \\
\hline $\begin{array}{l}\text { Wolmer et al. } \\
\text { (2011) }\end{array}$ & $\begin{array}{l}\text { Classroom } \\
\text { intervention } \\
\text { NOS }\end{array}$ & War/terrorism & $\begin{array}{l}\text { Middle } \\
\text { East }\end{array}$ & Pre-post & 754 & & UCLA & Group & 15 & Teacher & & 48.6 \\
\hline $\begin{array}{l}\text { Wolmer et al. } \\
\text { (2013) }\end{array}$ & $\begin{array}{l}\text { Classroom } \\
\text { intervention } \\
\text { NOS }\end{array}$ & War/terrorism & $\begin{array}{l}\text { Middle } \\
\text { East }\end{array}$ & Pre-post & 727 & & PTSDI-RI & Group & 14 & Teacher & & 50.8 \\
\hline $\begin{array}{l}\text { Kalantari et al. } \\
\text { (2012) }\end{array}$ & $\begin{array}{l}\text { Writing for } \\
\text { recovery }\end{array}$ & War/terrorism & $\begin{array}{l}\text { Middle } \\
\text { East }\end{array}$ & $\begin{array}{l}\text { RCT waitlist } \\
\text { control }\end{array}$ & 29 & 32 & TGIC & Group & 6 & Teacher & 14.6 & 45.0 \\
\hline $\begin{array}{l}\text { Zhu et al. } \\
\text { (2014) }\end{array}$ & Calligraphy & $\begin{array}{l}\text { Natural } \\
\text { disaster }\end{array}$ & Asia & $\begin{array}{l}\text { RCT waitlist } \\
\text { control }\end{array}$ & 129 & 81 & CRIES-13 & Group & 30 & Teacher & 10.5 & 49.6 \\
\hline $\begin{array}{l}\text { Layne et al. } \\
(2008)\end{array}$ & $\begin{array}{l}\text { Treating grief and } \\
\text { child trauma }\end{array}$ & War/terrorism & Europe & $\begin{array}{l}\text { RCT - active } \\
\text { control }\end{array}$ & 66 & 61 & PTSD-RI & Group & 17 & $\begin{array}{l}\text { Health care } \\
\text { specialist }\end{array}$ & 15.9 & 63.0 \\
\hline $\begin{array}{l}\text { Thabet et al. } \\
\text { (2005) }\end{array}$ & $\begin{array}{l}\text { Crisis } \\
\text { intervention/ } \\
\text { psychoeducation }\end{array}$ & War/terrorism & $\begin{array}{l}\text { Middle } \\
\text { East }\end{array}$ & $\begin{array}{l}\text { RCT - active } \\
\text { control }\end{array}$ & $47 / 22$ & $42 / 42$ & PTSD-RI & Group & $7 / 4$ & $\begin{array}{l}\text { Psychiatrist/ } \\
\text { psychologist }\end{array}$ & 12.6 & $32.0 / 100$ \\
\hline $\begin{array}{l}\text { Sakai et al. } \\
\text { (2010) }\end{array}$ & $\begin{array}{l}\text { Thought field } \\
\text { therapy }\end{array}$ & War/terrorism & Africa & Pre-post & 50 & & CROPS & Individual & 3 & $\begin{array}{l}\text { Psychiatrist/ } \\
\text { psychologist }\end{array}$ & & 46.0 \\
\hline
\end{tabular}




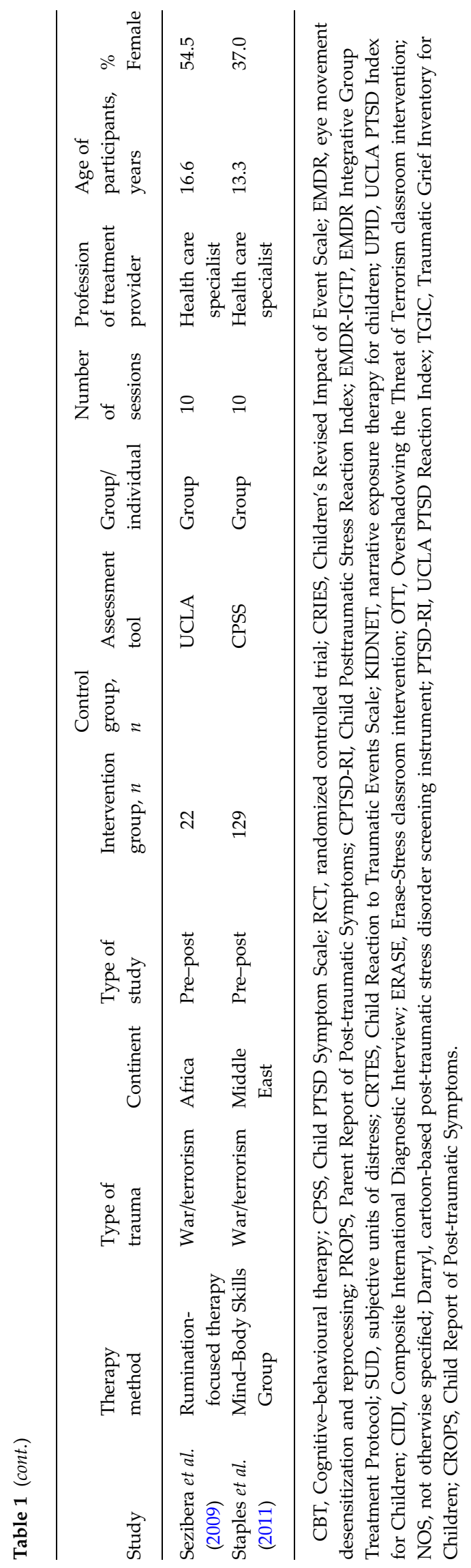

number of studies. One major strength of this study is the rigorous literature search, also including unpublished data. In comparison with previous reviews, we were able to report more data, e.g. on EMDR interventions. However, it has to be kept in mind that unpublished data have not been peer reviewed with regards to study design and analyses of data.

\section{Conclusion}

Specific treatments for traumatized children and adolescents after mass trauma can be recommended. They have been shown to be very effective in prepost comparisons and more effective than (waitlist) control groups. All specific treatment methods can be recommended, as all treatments with at least two studies (EMDR, CBT, KIDNET and classroom-based interventions) showed high effect sizes in pre-post comparisons and moderate effect sizes in controlled studies. Those evidence-based treatments should be preferably administered when seeking to help young survivors of disasters. As type of trauma (man-made or natural disasters) did not have an effect on treatment outcomes, those treatments can be recommended for a wide range of traumatic events. Treatments delivered by trained health care professionals have been shown to be more effective, which underlines the necessity of well-trained professionals conducting specific treatments. Since group treatment yielded lower effect sizes in pre-post comparisons, but no differences were found in controlled trials, no recommendation can be given. Furthermore, number of sessions was not significantly associated with treatment outcomes. In terms of cost-effectiveness, group treatments with a smaller number of treatment sessions could be considered, as they seem to yield similar effect sizes as individual treatments with a larger number of sessions. Especially in the light of vast numbers of minor refugees currently living in Europe, short-term treatments reaching a high number of children and adolescents simultaneously could be one solution. However, results may have been confounded, since participants with higher levels of impairment pretreatment may have needed more sessions of individual treatment, while they were transferred to individual therapy after group treatment in some studies. These findings underline the feasibility of stepped-care approaches with different levels of care for different needs to meet both the goals of outreach to a large group and providing adequate treatment for individuals with high impairment. The average age of children included in the primary studies was 11.8 years, with most children being over the age of 8 years. Studies on younger children are lacking and should be one focus of future research. 
Overall, studies were very heterogenic in terms of their quality, which was not systematically assessed in this review (i.e. use of validated assessment tools, reported data, sample size). Several studies included in this review had not been included in previous reviews, because they had not been published or lacked important information (i.e. means) in their reports. Future research would benefit from welldesigned studies using large sample sizes, which assess and report standardized outcome measures. This might be difficult in emergencies, when aid follows immediately after disasters without previous study plans. However, consistent evaluation could be accomplished by defining a toolkit for the evaluation of ad hoc treatments after disasters, which could, for example, be established by a working group of the World Health Organization or an international group of research academies.

\section{Acknowledgements}

This research received no specific grant from any funding agency, commercial or not-for-profit sectors. We would like to thank Dr Ignacio Jarero and Dr Arne Hofmann for providing unpublished data. We would also like to thank Julia Berger, M.Sc. and Lara Munz, B.Sc., for assisting with literature research and coding.

\section{Declaration of Interest}

R.C.B., A.W., F.K. and M.R. do not report conflicts of interest.

J.M.F. reports no financial interests or potential conflicts of interest. During the last 5 years, J.M.F. has received research funding from the European Union (EU), German Research Foundation (DFG), German Federal Ministry of Health (BMG), German Federal Ministry of Education and Research (BMBF), German Federal Ministry of Family, Senior Citizens, Women and Youth (BMFSFJ), German armed forces, several state ministries of social affairs, State Foundation Baden-Württemberg, Volkswagen Foundation, European Academy, Pontifical Gregorian University, Regionale Arbeitsstelle für Kindern und Jugendliche aus Zuwandererfamilien (RAZ), Christliches Jugenddorfwerk Deutschlands (CJD), Caritas, Diocese of Rottenburg-Stuttgart. Moreover, he received travel grants, honoraria and sponsoring for conferences and medical educational purposes from the DFG, American Academy of Child and Adolescent Psychiatry (AACAP), National Institute of Mental Health/National Institutes of Health, EU, Pro Helvetia, Janssen-Cilag (J\&J), Shire, several universities, professional associations, political foundations, and German federal and state ministries. He was part of clinical trials for Janssen-Cilag, Lundbeck, the $\mathrm{BMBF}$ and Servier and was in the steering committees and DSMB for Ludbeck and Servier. J.M.F. holds no stocks of pharmaceutical companies.

P.L.P. reports no financial interests or potential conflicts of interest. He received research grants from the BMBF, the German Federal Institute for Drugs and Medical Devices (BfArM), The DFG, the Baden-Wuerttemberg Foundation, the Volkswagen Foundation and served as principal investigator in a clinical study for Lundbeck. He received travel grants from the DFG, German Academic Exchange Service (DAAD) and the International Association for Child \& Adolescent Psychiatry and Allied Professions (IACAPAP). He is not a stockholder or shareholder in the pharmaceutical industry.

\section{References}

Adler-Nevo G, Manassis K (2005). Psychosocial treatment of pediatric posttraumatic stress disorder: the neglected field of single-incident trauma. Depression and Anxiety 22, 177-189.

Belhadj Kouider EB, Koglin U, Petermann F (2014). Emotional and behavioral problems in migrant children in Europe: a systematic review. European Child and Adolescent Psychiatry 23, 373-391.

Berger R, Gelkopf M (2009). School-based intervention for the treatment of tsunami-related distress in children: a quasi-randomized controlled trial. Psychotherapy and Psychosomatics 78, 364-371.

Berger R, Gelkopf M, Heineberg Y (2012). A teacherdelivered intervention for adolescents exposed to ongoing and intense traumatic war-related stress: a quasirandomized controlled study. Journal of Adolescent Health 51, 453-461.

Berger R, Pat-Horenczyk R, Gelkopf M (2007). School-based intervention for prevention and treatment of elementarystudents' terror-related distress in Israel: a quasirandomized controlled trial. Journal of Trauma Stress 20, 541-551.

Brown EJ, McQuaid J, Farina L, Ali R, Winnick-Gelles A (2006). Matching interventions to children's mental health needs: feasibility and acceptability of a pilot school-based trauma intervention program. Education and Treatment of Children 29, 257-286.

Catani C, Kohiladevy M, Ruf M, Schauer E, Elbert T, Neuner F (2009). Treating children traumatized by war and tsunami: a comparison between exposure therapy and meditation-relaxation in North-East Sri Lanka. BMC Psychiatry 9, 22.

Chemtob CM, Nakashima JP, Hamada RS (2002). Psychosocial intervention for postdisaster trauma symptoms in elementary school children: a controlled community field study. Archives of Pediatric and Adolescent Medicine 156, 211-216.

Chen Y, Shen WW, Gao K, Lam CS, Chang WC, Deng H (2014). Effectiveness RCT of a CBT intervention for youths 
who lost parents in the Sichuan, China, earthquake. Psychiatry Services 65, 259-262.

Chung YC, Kim D, Kim S, Bae H, Lee K, Go B (2014). Treatment response of affect regulation group therapy for recently traumatized school children. Journal of Korean Neuropsychiatric Association 53, 171-177.

de Roos C, Greenwald R, den Hollander-Gijsman M, Noorthoorn E, van Buuren S, de Jongh A (2011). A randomised comparison of cognitive behavioural therapy (CBT) and eye movement desensitisation and reprocessing (EMDR) in disaster-exposed children. European Journal of Psychotraumatology 2, 10.3402/ejpt.v2i0.5694.

Dorsey S, Briggs EC, Woods BA (2011). Cognitive-behavioral treatment for posttraumatic stress disorder in children and adolescents. Child and Adolescent Psychiatry Clinics of North America 20, 255-269.

Ehntholt KA, Smith PA, Yule W (2005). School-based cognitive-behavioral therapy group intervention for refugee children who have experiences war-related trauma. Clinical Child Psychology and Psychiatry 10, 235-250.

Ehntholt KA, Yule W (2006). Practitioner review: assessment and treatment of refugee children and adolescents who have experienced war-related trauma. Journal of Child Psychology and Psychiatry 47, 1197-1210.

Gelkopf M, Berger R (2009). A school-based, teachermediated prevention program (ERASE-Stress) for reducing terror-related traumatic reactions in Israeli youth: a quasirandomized controlled trial. Journal of Child Psychology and Psychiatry 50, 962-971.

Giannopoulou I, Dikaiakou A, Yule W (2006). Cognitivebehavioural group intervention for PTSD symptoms in children following the Athens 1999 earthquake: a pilot study. Clinical Child Psychology and Psychiatry 11, 543-553.

Gillies D, Taylor F, Gray C, O'Brien L, D'Abrew N (2013).

Psychological therapies for the treatment of post-traumatic stress disorder in children and adolescents (Review). Evidence Based Child Health 8, 1004-1116.

Hedges LV (1981). Distribution theory for Glass' estimator of effect size and related estimators. Journal of Educational Statistics 6, 107-128.

Jarero I, Artigas L, Hartung J (2006a). EMDR integrative group treatment protocol: a postdisaster trauma intervention for children and adults. Traumatology 12, 121-129.

Jarero I, Artigas L, Hartung J (2006b). EMDR integrative group treatment protocol: a postdisaster trauma intervention for children and adults - Acapulco sample. Traumatology 12, 121-129.

Jarero I, Artigas L, Hartung J (2006c). EMDR integrative group treatment protocol: a postdisaster trauma intervention for children and adults - El Salvador sample. Traumatology 12, 121-129.

Jarero I, Artigas L, Hartung J (2006d). EMDR integrative group treatment protocol: a postdisaster trauma intervention for children and adults - Nicaragua sample. Traumatology 12, 121-129.

Jarero I, Artigas L, Montero M (2008). The EMDR integrative group treatment protocol: application with child victims of a mass disaster. Journal of EMDR Practice and Research 2, 97-105.
Jordans MJ, Komproe IH, Tol WA, Kohrt BA, Luitel NP, Macy RD, de Jong JT (2010). Evaluation of a classroombased psychosocial intervention in conflict-affected Nepal: a cluster randomized controlled trial. Journal of Child Psychology and Psychiatry 51, 818-826.

Kalantari M, Yule W, Dyregrov A, Neshatdoost H, Ahmadi SJ (2012). Efficacy of writing for recovery on traumatic grief symptoms of Afghani refugee bereaved adolescents: a randomized control trial. Omega (Westport) 65, 139-150.

Kar N (2009). Psychological impact of disasters on children: review of assessment and interventions. World Journal of Pediatrics 5, 5-11.

Keeshin BR, Strawn JR (2014). Psychological and pharmacologic treatment of youth with posttraumatic stress disorder: an evidence-based review. Child and Adolescent Psychiatric Clinics of North America 23, 399-411, x.

Kowalik J, Weller J, Venter J, Drachman D (2011). Cognitive behavioral therapy for the treatment of pediatric posttraumatic stress disorder: a review and meta-analysis. Journal of Behavioral Therapy and Experimental Psychiatry 42, 405-413.

Layne CM, Saltzman WR, Poppleton L, Burlingame GM, Pasalic A, Durakovic E, Music M, Campara N, Dapo N, Arslanagic B, Steinberg AM, Pynoos RS (2008). Effectiveness of a school-based group psychotherapy program for war-exposed adolescents: a randomized controlled trial. Journal of the American Academy of Child and Adolescent Psychiatry 47, 1048-1062.

Mehrotra S (2014). Humanitarian projects and growth of EMDR therapy in Asia. Journal of EMDR Practice and Research 8, 252-259.

Morina N, Wicherts JM, Lobbrecht J, Priebe S (2014). Remission from post-traumatic stress disorder in adults: a systematic review and meta-analysis of long term outcome studies. Clinical Psychology Review 34, 249-255.

Newman E, Pfefferbaum B, Kirlic N, Tett R, Nelson S, Liles B (2014). Meta-analytic review of psychological interventions for children survivors of natural and man-made disasters. Current Psychiatry Reports 16, 462.

O'Callaghan P, McMullen J, Shannon C, Rafferty H (2015). Comparing a trauma focused and non trauma focused intervention with war affected Congolese youth: a preliminary randomised trial. Intervention 13, 28-44.

Onyut LP, Neuner F, Schauer E, Ertl V, Odenwald M, Schauer M, Elbert T (2005). Narrative exposure therapy as a treatment for child war survivors with posttraumatic stress disorder: two case reports and a pilot study in an African refugee settlement. BMC Psychiatry 5, 7.

Peltonen K, Punamaki RL (2010). Preventive interventions among children exposed to trauma of armed conflict: a literature review. Aggressive Behavior 36, 95-116.

Pfefferbaum B, Newman E, Nelson SD (2014a). Mental health interventions for children exposed to disasters and terrorism. Journal of Child Adolescent Psychopharmacology 24, 24-31.

Pfefferbaum B, Newman E, Nelson SD, Liles BD, Tett RP, Varma V, Nitiema P (2014b). Research methodology used in studies of child disaster mental health interventions for posttraumatic stress. Comprehensive Psychiatry 55, 11-24. 
Pityaratstian N, Liamwanich K, Ngamsamut N, Narkpongphun A, Chinajitphant N, Burapakajornpong N, Thongphitakwong W, Khunchit W, Weerapakorn W, Rojanapornthip B, Jayasvasti K (2007). Cognitivebehavioral intervention for young tsunami victims. Journal of the Medical Association Thailand 90, 518-523.

Pityaratstian N, Piyasil V, Ketumarn P, Sitdhiraksa N, Ularntinon S, Pariwatcharakul P (2015). Randomized controlled trial of group cognitive behavioural therapy for post-traumatic stress disorder in children and adolescents exposed to tsunami in Thailand. Behavioral Cognitive Psychotherapy 43, 549-561.

R Development Core Team (2008). $R$ : a Language and Environment for Statistical Computing. R Foundation for Statistical Computing: Vienna.

Rachamim L, Nacasch N, Shafran N, Tzur D, GilboaSchechtman E (2009). Exposure-based therapy for posttraumatic stress disorder in children and adults. Israelian Journal of Psychiatry and Related Sciences 46, 274-281.

Rolfsnes ES, Idsoe T (2011). School-based intervention programs for PTSD symptoms: a review and meta-analysis. Journal of Traumatic Stress 24, 155-165.

Ronholt S, Karsberg S, Elklit A (2013). Preliminary evidence for a classroom based psychosocial intervention for disaster exposed children with posttraumatic stress symptomatology. Child Youth Care Forum 42, 617-631.

Rowe CL, Liddle HA (2008). When the levee breaks: treating adolescents and families in the aftermath of hurricane Katrina. Journal of Marital Family Therapy 34, 132-148.

Sakai CE, Connolly SM, Oas P (2010). Treatment of PTSD in Rwandan child genocide survivors using thought field therapy. International Journal of Emergency Mental Health 12, 41-49.

Salcioglu E, Basoglu M (2008). Psychological effects of earthquakes in children: prospects for brief behavioral treatment. World Journal of Pediatrics 4, 165-172.

Sezibera V, Van Broeck N, Philippot P (2009). Intervening on persistent posttraumatic stress disorder: ruminationfocused cognitive and behavioral therapy in a population of young survivors of the 1994 genocide in Rwanda. Journal of Cognitive Psychotherapy: an International Quarterly 23, 107-113.

Smith P, Perrin S, Dalgleish T, Meiser-Stedman R, Clark DM, Yule W (2013). Treatment of posttraumatic stress disorder in children and adolescents. Current Opinion in Psychiatry 26, 66-72.

Staples JK, Atti A, Ahmed J, Gordon JS (2011). Mind-body skills groups for posttraumatic stress disorder and depression symptoms in Palestinian children and adolescents in Gaza. International Journal of Stress Management 18, 246-262.
Tang TC, Yang P, Yen CF, Liu TL (2015). Eye movement desensitization and reprocessing for treating psychological disturbances in Taiwanese adolescents who experienced Typhoon Morakot. Kaohsiung Journal of Medical Sciences 31, 363-369.

Taylor LK, Weems CF (2011). Cognitive-behavior therapy for disaster-exposed youth with posttraumatic stress: results from a multiple-baseline examination. Behavior Therapy 42, 349-363.

Thabet AA, Vostanis P, Karim K (2005). Group crisis intervention for children during ongoing war conflict. European Journal of Child and Adolescent Psychiatry 14, 262-269.

UNHCR (2016). Figures at a Glance (http://www.unhcr.org/ uk/figures-at-a-glance.html).

Viechtbauer W (2010). Conducting meta-analyses in R with the metafor package. Journal of Statistical Software 36, 1-48.

Wadaa NN, Zaharim NM, Alqashan HF (2010). The use of EMDR in treatment of traumatized Iraqi children. Digest of Middle East Studies 19, 26-36.

Wang CW, Chan CL, Ho RT (2013). Prevalence and trajectory of psychopathology among child and adolescent survivors of disasters: a systematic review of epidemiological studies across 1987-2011. Social Psychiatry and Psychiatric Epidemiology 48, 1697-1720.

Weems CF, Graham RA (2014). Resilience and trajectories of posttraumatic stress among youth exposed to disaster. Journal of Child and Adolescent Pharmacology 24, 2-8.

Witt A, Rassenhofer M, Fegert JM, Plener PL (2015). Hilfebedarf und Hilfsangebote in der Versorgung von unbegleiteten minderjährigen Flüchtlingen. Kindheit und Entwicklung 24, 209-224.

Wolmer L, Hamiel D, Barchas JD, Slone M, Laor N (2011). Teacher-delivered resilience-focused intervention in schools with traumatized children following the second Lebanon War. Journal of Traumatic Stress 24, 309-316.

Wolmer L, Hamiel D, Slone M, Faians M, Picker M, Adiv T, Laor N (2013). Post-traumatic reaction of Israeli Jewish and Arab children exposed to rocket attacks before and after teacher-delivered intervention. Israel Journal of Psychiatry and Related Sciences 50, 165-172.

Wolmer L, Laor N, Yazgan Y (2003). School reactivation programs after disaster: could teachers serve as clinical mediators? Child and Adolescent Psychiatry Clinics of North America 12, 363-381.

Zhu Z, Wang R, Kao HS, Zong Y, Liu Z, Tang S, Xu M, Liu IC, Lam SP (2014). Effect of calligraphy training on hyperarousal symptoms for childhood survivors of the 2008 China earthquakes. Journal of Neuropsychiatric Disease and Treatment 10, 977-985. 